\title{
THE RELATIONSHIP BETWEEN SELF-REPORTED TRAFFIC CRASHES AND DRIVER BEHAVIOR IN THE ROAD TRANSPORTATION OF GOODS AND FREIGHT IN BALI
}

\author{
Dewa Made Priyantha Wedagama ${ }^{*}$, Darren Wishart ${ }^{2}$ \\ ${ }^{1}$ Department of Civil Engineering, Faculty of Engineering, Udayana University, \\ Kampus Bukit Jimbaran, Badung 80361, Bali, Indonesia \\ ${ }^{2}$ CARRS-Q Queensland University of Technology, Kelvin Grove Campus, Level 4, K Block, \\ 130 Victoria Park Road Q 4059 Brisbane, Australia
}

(Received: November 2017 / Revised: February 2018 / Accepted: March 2018)

\begin{abstract}
Road safety stakeholders in Bali have highlighted the need to investigate and better understand road user behavior as a means of reducing the high number of crashes in the goods and freight distribution sector. This study aims to analyze the relationship between driver behavior and traffic crashes reported by drivers transporting goods and freight in Denpasar, Bali. A driving safety survey was distributed to 350 goods and freight transport drivers to obtain a range of demographic information, self-reported crash and offence data, and psychosocial data associated with driving safety. Analysis identified four areas of concern with distinctions between different driving practices within the sample, consisting of aggressive driving behavior, driving errors, traffic code violations and normlessness. The results of this study demonstrate that normlessness consisting of behaviors such as taking a slight risk when overtaking and ignoring speed limits were the most common forms of unsafe behavior reported by the goods vehicle transport drivers. The study found that speeding influenced more self-reported driving errors, aggressive behaviors, traffic rule violations and crashes. In addition, drink driving was found to be positively related to traffic crashes. The implications of these results are discussed.
\end{abstract}

Keywords: Driver behaviors; Goods vehicles; Road safety; Traffic crashes

\section{INTRODUCTION}

Annually, there are estimated to be more than 38,000 road traffic fatalities in Indonesia (The World Health Organization, 2015). This number includes both passengers and goods transport. Goods transport is the conveyance of materials or products from one place to another using different modes and networks, and is usually expressed in ton-kilometers, while passenger transport is the carrying of people and is expressed in passenger-kilometers.

As Indonesia is a major distribution economy in the South Pacific region, goods distribution and transport are becoming an increasing focus of road safety stakeholders. Within the goods distribution and transport sector in Indonesia, overloading has been identified as a major contributor to traffic crashes (Indonesian National Police, 2014). Indonesian crash data over a five year period (2009-2013) showed that this is a highly relevant issue, with the number of violations by freight transport firms reported as representing $8.5 \%$ of the total number of traffic violations. In addition, there was an average of $21.2 \%$ of freight traffic crashes of the total

\footnotetext{
${ }^{*}$ Corresponding author's email: priyantha@civil.unud.ac.id, Tel. +62-361- 703385, Fax. +62-361- 224124 Permalink/DOI: https://dx.doi.org/10.14716/ijtech.v9i3.960
} 
number of traffic crashes per year over the 5 year period from 2009 to 2013 (Indonesian National Police, 2014).

While much of the responsibility for driving safely ultimately rests with the driver of a vehicle (Zuraida et al., 2017), the load carrying capacity (overloading) of a vehicle can be influenced by factors that are both individual and also organizational in nature. For example, organizational factors could include circumstances whereby an organization is endeavoring to transfer freight and goods with the least amount of resources (eg. to save time or use of vehicles), which may contribute to the overloading of vehicles. In addition, an organizational culture may exist that encourages drivers to overload vehicles, particularly in developing countries, where the enforcement of legal load requirements may not be stringently enforced by the authorities. Furthermore, in developing countries such as Indonesia, utilisation of, or a lack of, resources such as vehicles fit for purpose, may be one of the main contributing factors to freight and goods distribution vehicle overloading. There also exists a multitude of individual factors that can influence freight and goods distribution vehicle transport safety. Despite the prevalence of crashes, little attention has been focused on the behaviors of goods vehicle drivers in Indonesia.

Meanwhile, goods and freight distribution vehicle transport movements in Bali play an important role in Indonesia, as they connect lines of freight between Java and the west, and the Nusa Tenggara islands to the east. In comparison with river and ferry services, the proportion of road transportation in Bali from 2006 to 2011 was $91.25 \%$ of total goods and freight transport. In other words, road transportation makes a significant contribution towards goods and freight transport in Bali. However, it should also be noted that within Bali various types of vehicles are permitted to deliver freight and goods, including vans and small sedans, light tray back trucks, and utility and heavy truck vehicles. In 2015, there were a total of 113,937 heavy transport vehicles registered in Bali, of which 78,720 were trucks and 35,217 were pick up vehicles. In addition, in Denpasar alone, there were a total of 45,115 heavy transport vehicles registered, consisting of 32,720 trucks and 12,395 pick-up vehicles (Statistics of Bali Province, 2015). Consequently, the goods and freight distribution transport sector comprises a large proportion of the registered vehicles in Denpasar, accounting for approximately $40 \%$ of all vehicles registered in Bali.

As a means of addressing the trauma associated with road crashes, particularly in developing countries, there is a need to have a better understanding of the factors associated with unsafe and risky driving behaviors, particularly in heavily congested and urban roads along typical transport and goods distribution corridors. Previous research on driving safety within the work sector in Indonesia is scarce; however, research in other countries has utilized a variety of selfreporting measures to better understand the influential factors within the work driving setting. For example, research in the Australian setting has identified several contributing factors to fleet vehicle crashes, including age, disobeying traffic rules, alcohol and drugs, speeding, inexperience, inattention, fatigue, negligence and road conditions (Wishart \& Davey, 2004). Other research has also identified higher crash rates and less engagement in vehicle checking practices in work vehicles, in comparison to personal vehicles (Newnam et al., 2002). Similarly, fleet drivers have been shown to have the tendency to engage in speeding behaviors and considered speeding to be acceptable, in contrast to other factors such as drink driving, tailgating or risky overtaking manoeuvres (Davey et al., 2006; Freeman et al., 2008). Other factors such as attitude, behavior, knowledge and hazard perception have also been shown to be highly correlated with the self-reported collisions of fleet drivers.

More specifically, attitude and behavior scores, distance travelled, driver age and personality have been shown to have a statistically significant relationship with the involvement in collisions of fleet drivers (Darby et al., 2009). Within the heavy vehicle freight distribution 
sector, law abiding driving behavior in trucks has been found to be more related to attitudes, subjective norms and intentions than perceived behavioral control (Poulter et al., 2008). However, other research within this area has identified that driver and company perceptions differ in regards to fatigue and fatigue management, particularly in relation to the causes and level of fatigue, and the strategies that should be used to manage it (Arnold et al., 1997). This study therefore aims to investigate the effect of individual factors on goods and freight distribution vehicle transport safety, using Denpasar, the capital city of Bali Province, Indonesia, as the case study area. More specifically, the study investigates the relationship between self-reported traffic crashes and the behaviors of goods and freight distribution vehicle transport drivers, highlighting the influence of driver behavior and other contributing factors to traffic crashes in the road transportation of goods and freight. It is therefore essential to place the behavioral factors within a relevant theoretical structure to comprehend, foresee and deal with goods and freight-related driver safety.

\section{METHODS}

\subsection{Participants and Procedure}

The researchers approached goods and freight distribution vehicle transport drivers at various organizational distribution locations, such as shops and wholesale/manufacturing premises, in Denpasar. The participants were advised of the aim of the survey and their cooperation to take part was requested. A total of 350 individuals participated in the study, who were all male drivers of vehicles used to transport goods and freight. The data indicated that on average respondents were around 35 years of age (varying between 20 and 63 years old). The type of vehicles reported as being used for freight and goods distribution by the participants consisted of light vehicles such as sedans, hatchbacks, station wagons and utility vehicles $(21.4 \%)$, fourwheel drives (26\%), trucks (36.3\%) and others (16.3\%).

The data indicated that the majority of participants had not been involved in a traffic crash in the previous 12 months, with 70.6\% indicating having had no non-work-related crashes, and $85.4 \%$ having had no work-related crashes. Of the $103(29.4 \%)$ drivers who reported having been involved in a work crash in the previous 12 months, 77 stated that they had had only one crash. A total of $51(14.6 \%)$ drivers reported that they had been involved in a non-work crash in the previous 12 months, with 26 of these stating that only one crash had occurred. In brief, a total sample of 350 respondents was used for the analysis. Of these, 103 had been involved in traffic crashes $(\operatorname{code}=1)$, while the remainder had not $(\operatorname{code}=0)$.

Self-reporting of traffic offences indicated that $70.6 \%$ of the participants had not committed a traffic offence during work hours, and $74.9 \%$ had not done so outside of work hours. The participants also reported that $21.4 \%$ of them did most of their driving on urban roads, while $26 \%$ travelled mostly on a mixture of both urban and rural roads. A total of $36.3 \%$ of the sample drove only on rural roads, and $16.3 \%$ mostly off road.

With regard to driving experience and exposure, on average the participants had been driving a work vehicle for about 14 years (varying between 2 and 40 years). The highest proportion of the sample, $30 \%$, drove between 1 and 10 hours per week, with $27.7 \%$ estimating that they drove between 30,000 and 40,000 km per year.

\subsection{Materials}

A work driving safety questionnaire previously utilized within the Australian work driving setting (Freeman et al., 2008) was used in this study, adapted and translated into the Indonesian language. The work questionnaire contained modified versions of the Driver Behavior Questionnaire (DBQ) (Reason et al., 1990); the Driver Attitude Questionnaire (DAQ) (Parker et al., 1996); the Safety Climate Questionnaire (SCQ-MD) (Glendon \& Stanton, 2000); the Thrill 
Seeking Subscale from the Driver Stress Inventory (Matthews et al., 1997); and several contemporary issues specifically connected with work driving safety (e.g. fatigue).

Behavior and attitude variables were derived from two types of question. The first type consisted of a total of 44 questions related to driver experiences (expressed by $1=$ never to $7=$ always) when driving for work over the previous 6 months. The second type comprised a total of 20 questions on perceptions of and feelings towards work driving, and the readiness to change risky driving behavior (expressed from $1=$ strongly disagree to $7=$ strongly agree). All these variables were subjected to Principal Component Analysis (PCA). With regard to the results, three behavior, attitude and thrill seeking variables were specified in subscales 4-6 in Table 1.

Table 1 Questionnaire items

\begin{tabular}{cl}
\hline No. & \multicolumn{1}{c}{ Items } \\
\hline 1 & Demographic information (age, driving license, gender) \\
2 & Exposure (hours per week driving, km travelled per year) \\
3 & Crashes and offences (in the last 12 months) \\
4 & Driver Behavior items (DBQ plus extra contemporary items) \\
5 & Driver Attitude Questionnaire \\
6 & Readiness to change (derived from Prochaska \& DiClemente, 1984) \\
\hline
\end{tabular}

Table 1 shows the questionnaire items, which comprised six sections consisting of a total of 73 items. The study employed the self-reporting method because it specifies similar participants with various risky behaviors and is documented more suitably (Rhodes \& Pivik, 2011). Prejudice towards reacting in a socially desirable way was also discovered to be fairly insignificant in the driver behavior answers (Lajunen \& Summala, 2003). Self-report measures have also been shown to identify "at risk" drivers in professional drivers' involvement with aberrant driving behaviors in fleet based settings (Freeman et al., 2009).

\subsection{Data Analysis Techniques}

Factor analysis was used to examine the behavior and perception variables included in the model construction. Principal Component Analysis (PCA) was employed for each behavior, attitude and thrill seeking variable (subscales 4-6 in Table 1). The maximum variance method (MVM) was utilized to examine the principal components. Statistically, Cronbach's alpha was used to measure the internal consistency between these behavior and perception variables. The variables resulting from the factor analysis, together with demographic, exposure and crash variables, were entered into the model construction.

The modelling were carried out with logistic regression models to deal with the binary nature of the dependent variables, such as involvement in traffic crashes (code $=1$ ) or no involvement in traffic crashes (code $=0$ ). Two logistic regression models were constructed to examine the predictive ability of driver behavior and attitudes to work and non-work crashes, above and beyond simple driving exposure. Driving exposure consisted of hours of driving/week and $\mathrm{km}$ travelled/year. In order to identify more contributing factors on traffic crashes, beyond those involving the demographic, behavior and perception variables, self-reported crashes by the participants were classified into crashes during working and non-working hours.

\section{RESULTS AND DISCUSSION}

\subsection{Principal Component Analysis (PCA)}

Table 2 shows the loading factors of the seven behavior items in a group of driving experiences in the previous six months, consisting of items no 4.14 (failure to check rear view mirror before 
pulling out or changing lanes); 4.18 (racing away from traffic lights with the intention of beating the driver next to you); 4.20 (driving even though you suspect you may be over the legal blood-alcohol limit); 4.21 (disregarding the speed limit on a residential road); 4.22 (exceeding the speed limit on a residential road without realising it); 4.23 (becoming angered by another driver and giving chase); and 4.32 (having one or two alcoholic drinks before driving for work). Statistically, these items explained variances greater than $20 \%$ and Cronbach's Alpha was used to measure loading factors more than 0.7 (Hooper et al., 2008).

In addition, items relating to driver attitude were significant and classified into two groups. The first group consisted of items 5.9 (it's ok to have a few alcoholic drinks before driving home after work at the end of the weekend) and 5.12 (speed limits are often set too low, with the result that many drivers ignore them), while the second group contained items 5.3 (it is quite acceptable to take a slight risk when overtaking) and 5.6 (some people can drive perfectly, even when they only leave a small gap between the vehicle in front). Item no 6 were classified into a factor which justified less than $20 \%$ of variance, which is statistically insignificant (Hooper et al., 2008). As a result, these items are not included in the model development. The variables and factors employed in the model construction are shown in Table 2.

Table 2 Behavior and perception variable selection using PCA

\begin{tabular}{|c|c|c|c|c|}
\hline No & Factors & $\begin{array}{c}\text { Variance } \\
\text { Explained } \\
(>20 \%)\end{array}$ & $\begin{array}{l}\text { Question } \\
\text { No. }\end{array}$ & $\begin{array}{c}\text { Cronbach's } \\
\text { Alpha } \\
(>0.7)\end{array}$ \\
\hline 1. & $\begin{array}{l}\text { Driving experience in the past } 6 \\
\text { months }\end{array}$ & $20.381 \%$ & $\begin{array}{l}4.14 \\
4.18 \\
4.20 \\
4.21 \\
4.22 \\
4.23 \\
4.32\end{array}$ & $\begin{array}{l}0.707 \\
0.816 \\
0.884 \\
0.871 \\
0.706 \\
0.720 \\
0.761\end{array}$ \\
\hline 2. & $\begin{array}{l}\text { Attitude towards alcohol \& speed } \\
\text { violations }\end{array}$ & 22.326 & $\begin{array}{r}5.9 \\
5.12\end{array}$ & $\begin{array}{l}0.817 \\
0.782\end{array}$ \\
\hline 3. & $\begin{array}{l}\text { Attitude towards risky overtaking } \\
\text { and following too closely }\end{array}$ & 20.039 & $\begin{array}{l}5.3 \\
5.6\end{array}$ & $\begin{array}{l}0.831 \\
0.775\end{array}$ \\
\hline
\end{tabular}

With reference to a three factor solution shown in Table 2, the first factor contains seven items associated with a mixture of aggressive driving behaviors (questions 4.18 and 4.23), driving errors (questions 4.14 and 4.22) and traffic code violations (questions 4.20, 4.21 and 4.32). All the items in the second and third factors represent attitudes towards unsafe and risky driving behaviors, associated with alcohol, speeding, risky overtaking and distance between other vehicles. The analysis indicates that four types of behavior, traffic code violations, driving errors, aggressive driving behaviors and driver attitudes, are significant in influencing goods vehicle driver behavior in Denpasar, Bali. These findings are very similar to those of a study by Davey et al. (2007), which examined the self-reported driving behaviors of Australian fleet drivers and found a three significant factor, identified as aggressive driving violations, errors and highway code violations.

\subsection{Prediction of Traffic Crashes}

The variables of interest were entered into the logistic regression model using SPSS version 15 with the exposure factors first, followed by the behaviors. Both chi squares (steps 1 and 2 in Table 3) for the traffic crashes during working hours model were $66.81(p<0.001)$; for the H-L (Hosmer-Lemeshow) test less than 0.05 and $168.92(p<0.001)$ and H-L test greater than 0.05, while both chi squares (steps 1 and 2 in Table 4 ) for the non-working hours model were 126.29 
( $p<0.001$ and H-L Test less than 0.05) and $327.76(p<0.001$ and H-L Test greater than 0.05). Considering these results, steps 2 in Tables 3 and 4 for both traffic crashes during working and non-working hours models were statistically significant.

As shown in Table 3 (step 2), hours of driving per week and age of driver were significantly and negatively related to traffic crashes during working hours. In addition, the goods vehicle drivers' responses to the items 'race away from traffic lights with the intention of beating the driver next to you', 'become angered by another driver and give chase', and 'speed limits are often set too low with the result that many drivers ignore them' were significantly and negatively related to traffic crashes during working hours. In contrast, the goods vehicle drivers' responses to the statements 'drive even though you suspect you may be over the legal blood-alcohol limit', 'it is quite acceptable to take a slight risk when overtaking' and 'it's ok to have a few alcoholic drinks before driving home after work at the end of the weekend' were significantly and positively linked to traffic crashes during working hours. In other words, driving experiences and normlessness were generally significant and both positively and negatively influenced goods vehicle drivers' involvement in traffic crashes during working hours in Denpasar.

Table 3 Working hours logistic regression model

\begin{tabular}{|c|c|c|c|c|c|c|c|}
\hline \multirow{2}{*}{ Step 1} & \multirow{2}{*}{$\beta$} & \multirow{2}{*}{ S.E. } & \multirow{2}{*}{ Wald } & \multirow{2}{*}{ Sig. } & \multirow{2}{*}{$\operatorname{Exp}(B)$} & \multicolumn{2}{|c|}{$95 \%$ C.I.for $\operatorname{EXP}(\beta)$} \\
\hline & & & & & & Lower & Upper \\
\hline Hours of driving/week & -.368 & .103 & 12.745 & .000 & .692 & .565 & .847 \\
\hline $\mathrm{Km}$ travelled/year & .088 & .077 & 1.297 & .255 & 1.092 & .939 & 1.270 \\
\hline \multirow{2}{*}{ Step 2} & \multirow{2}{*}{$\beta$} & \multirow{2}{*}{ S.E. } & \multirow{2}{*}{ Wald } & \multirow{2}{*}{ Sig. } & \multirow{2}{*}{$\operatorname{Exp}(B)$} & \multicolumn{2}{|c|}{$95 \%$ C.I.for $\operatorname{EXP}(\beta)$} \\
\hline & & & & & & Lower & Upper \\
\hline Hours of driving/week & -.556 & .142 & 15.238 & $.000 * * *$ & .573 & .434 & .758 \\
\hline $\mathrm{Km}$ travelled/year & .096 & .121 & .627 & .428 & 1.100 & .868 & 1.394 \\
\hline Age -9 & -.067 & .024 & 7.437 & $.006 * *$ & .936 & .892 & .981 \\
\hline License & .045 & .037 & 1.515 & .218 & 1.046 & .974 & 1.124 \\
\hline Fail to check rear-view mirror & -.135 & .236 & .328 & .567 & .873 & .550 & 1.388 \\
\hline Race away from traffic lights & -.974 & .325 & 8.992 & $.003 * *$ & .377 & .200 & .714 \\
\hline Exceed the legal blood-alcohol limit & .918 & .298 & 9.481 & $.002 * *$ & 2.504 & 1.396 & 4.491 \\
\hline Speed on residential roads & .331 & .310 & 1.144 & .285 & 1.393 & .759 & 2.555 \\
\hline Unaware of speeding on residential roads & -.234 & .249 & .885 & .347 & .791 & .486 & 1.289 \\
\hline Angered and chase other drivers &.- .417 & .204 & 4.189 & $.041 *$ & .659 & .442 & .982 \\
\hline Drink before driving for work & .304 & .251 & 1.465 & .226 & 1.356 & .828 & 2.218 \\
\hline Take slight risks when overtaking & .561 & .114 & 24.334 & $.000 * *$ & 1.752 & 1.402 & 2.189 \\
\hline Small gap between the vehicle ahead & -.187 & .118 & 2.516 & .113 & .829 & .658 & 1.045 \\
\hline Drink before driving home & 1.126 & .237 & 22.575 & $.000 * *$ & 3.084 & 1.938 & 4.907 \\
\hline Speed limits are often set too low & -.610 & .204 & 8.930 & $.003 * *$ & .543 & .364 & .811 \\
\hline
\end{tabular}

Note: $*$ p <.0.05; **p<.0.01; C.I : Confidence Interval

Table 4 (step 2) shows that kilometres travelled per year and driving license ownership were significantly and positively related to traffic crashes during non-working hours. In contrast to traffic crashes during working hours, driver age was negatively associated with traffic crashes during non-working hours. In addition, goods vehicle drivers' responses to the items 'fail to check rearview mirror before pulling out or changing lanes' and 'it is quite acceptable to take a slight risk when overtaking' were significantly and positively related to traffic crashes during non-working hours. In contrast, their responses to the statement 'some people can drive perfectly even when they only leave a small gap behind the vehicle in front' were significantly and negatively linked to traffic crashes during non-working hours. Similar to traffic crashes 
during working hours, driving experience and normlessness were generally significant and both positively and negatively influenced traffic crashes during non-working hours.

Table 4 Non-working hours logistic regression model

\begin{tabular}{|c|c|c|c|c|c|c|c|}
\hline \multirow{2}{*}{ Step 1} & \multirow{2}{*}{$\beta$} & \multirow{2}{*}{ S.E. } & \multirow{2}{*}{ Wald } & \multirow{2}{*}{ Sig. } & \multirow{2}{*}{$\operatorname{Exp}(B)$} & \multicolumn{2}{|c|}{$95 \%$ C.I.for $\operatorname{EXP}(\beta)$} \\
\hline & & & & & & Lower & Upper \\
\hline Hours of driving/week & -.206 & .120 & 2.927 & .087 & .814 & .643 & 1.030 \\
\hline $\mathrm{Km}$ travelled/year & -.162 & .091 & 3.125 & .077 & .851 & .711 & 1.018 \\
\hline \multirow{2}{*}{ Step 2} & \multirow{2}{*}{$\beta$} & \multirow{2}{*}{ S.E. } & \multirow{2}{*}{ Wald } & \multirow{2}{*}{ Sig. } & \multirow{2}{*}{$\operatorname{Exp}(B)$} & \multicolumn{2}{|c|}{$95 \%$ C.I.for $\operatorname{EXP}(\beta)$} \\
\hline & & & & & & Lower & Upper \\
\hline Hours of driving/week & -.145 & .216 & .449 & .503 & .865 & .566 & 1.322 \\
\hline $\mathrm{Km}$ travelled/year & .430 & .176 & 5.928 & $.015^{*}$ & 1.537 & 1.087 & 2.171 \\
\hline Age & -.222 & .046 & 22.893 & $.000 * *$ & .801 & .732 & .877 \\
\hline License & .181 & .060 & 9.165 & $.002 * *$ & 1.199 & 1.066 & 1.348 \\
\hline Fail to check rear-view mirror & 2.422 & .491 & 24.340 & $.000 * *$ & 11.267 & 4.305 & 29.487 \\
\hline Race away from traffic lights & -.565 & .567 & .996 & .318 & .568 & .187 & 1.725 \\
\hline Exceed the legal blood-alcohol limit & -1.239 & .655 & 3.576 & .059 & .290 & .080 & 1.046 \\
\hline Speed on residential roads & -.319 & .615 & .270 & .604 & .727 & .218 & 2.425 \\
\hline Unaware of speeding on residential roads & .483 & .500 & .932 & .334 & 1.621 & .608 & 4.320 \\
\hline Angered and chase other drivers & -.464 & .324 & 2.059 & .151 & .629 & .333 & 1.185 \\
\hline Drink before driving for work & -.221 & .428 & .266 & .606 & .802 & .346 & 1.857 \\
\hline Take slight risks when overtaking & .707 & .168 & 17.719 & $.000 * *$ & 2.028 & 1.459 & 2.818 \\
\hline Small gap between vehicle ahead & -.738 & .212 & 12.094 & $.001 * *$ & .478 & .316 & .725 \\
\hline Drink before driving home & .057 & .306 & .035 & .851 & 1.059 & .582 & 1.927 \\
\hline Speed limits are often set too low & .027 & .249 & .012 & .913 & 1.028 & 631 & 1.674 \\
\hline
\end{tabular}

Note: $* \mathrm{p}<.0 .05 * * \mathrm{p}<.0 .01 ;$ C.I : Confidence Interval

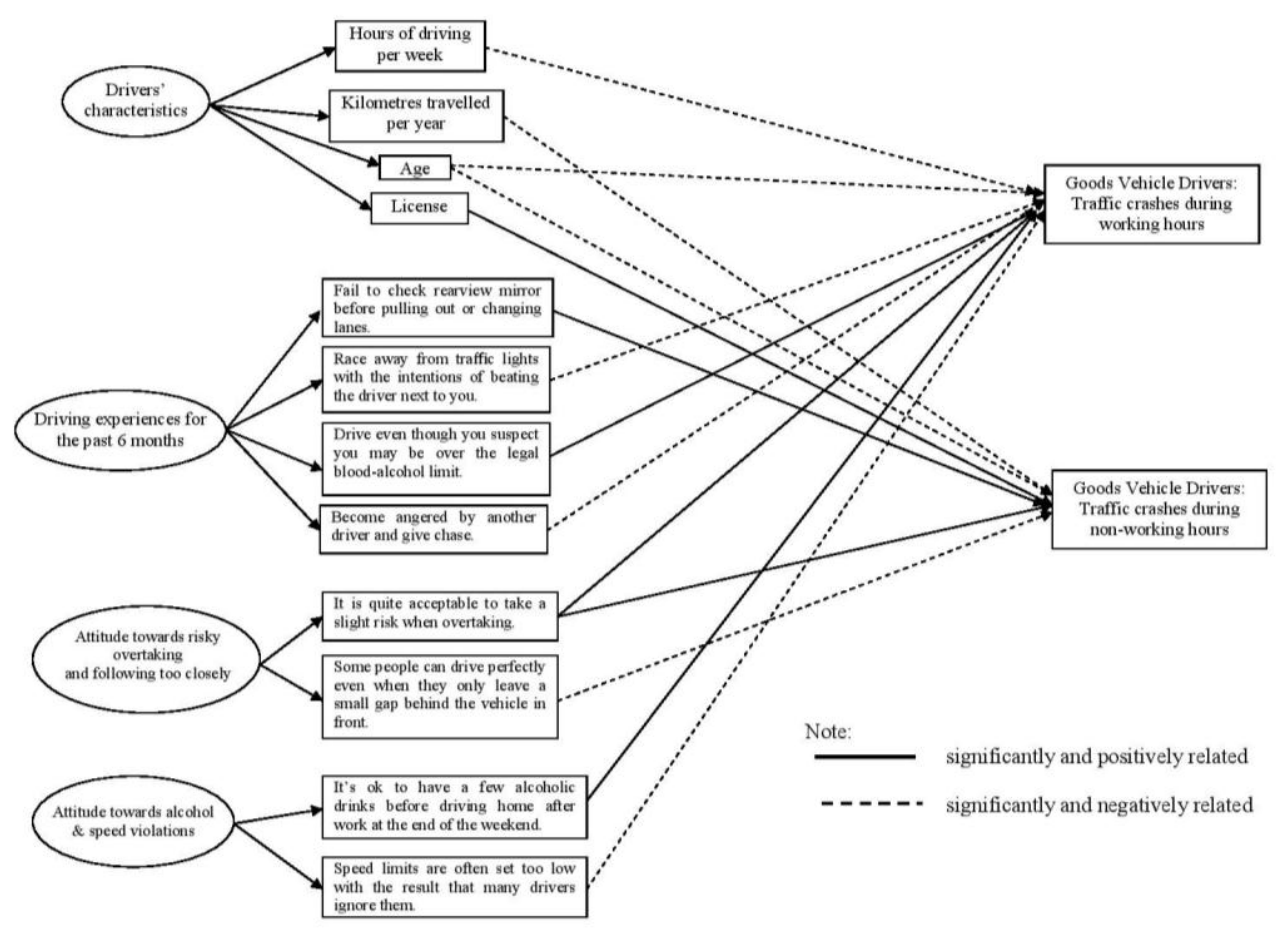

Figure 1 Influencing factors of goods vehicle driver traffic crashes

All the relationships between self-reported traffic crashes and the behaviors of goods vehicle drivers in Denpasar, and the explanations of Tables 3 and 4, are summarized and depicted in 
Figure 1. The ovals and rectangles in Figure 1 specify the latent and observed variables respectively. These methods were considered appropriate as the nature of the problem combines behavioral and perception factors, and demographic, exposure and crash variables.

The revised DBQ was used as a measurement tool to examine motorists'self-reported driving behaviors (Lajunen \& Summala, 2003; de Winter \& Dodou, 2010). Subsequently, it was employed to investigate the factor structure and predictive ability within this field of road safety (Sullman et al., 2002; Davey et al., 2007). The utilisation of the revised DBQ in the respondents of goods vehicle drivers for this study produced a number of interesting findings.

The changes to the DBQ translated into the Indonesian language to reflect the circumstances of goods vehicle drivers in Denpasar demonstrated good reliability. The investigation of the overall scores for the five items revealed relative internal consistency, in which traffic rule violations (i.e. drink driving and speeding on residential roads) appear to be reliable. This is consistent with the findings of previous studies, that fleet drivers were more likely to report being engaged in speeding behavior (Davey et al., 2006; Freeman et al., 2008). Considering the work and time pressures frequently imposed on goods vehicle drivers, speeding violations are clearly the most common form of aberrant behavior both shown and reported by the drivers. This may confirm the general idea that minor speeding violations are acceptable in some situations and do not pose a serious road safety risk (Davey et al., 2006). Furthermore, speeding violations during working hours may result from time and work pressures which possibly lead to aggressive violations (Davey et al., 2006).

Meanwhile, drink driving is perceived to be less of a problem by goods vehicle drivers in Denpasar, so they may not believe that it poses a serious road safety risk. In fact, a serious impact of drink driving with respect to road safety is that the muscles weaken. This means that in the case of a crash, the injuries will be more severe if a road user has consumed alcohol. While goods vehicle drivers show up better with regard to alcohol than the average motorist involved in alcohol-related crashes, there is considerably less tolerance for drink driving among drivers whilst working. The victims of crashes involving goods vehicles, regardless of which driver is at fault, are most often the passengers and those in smaller vehicles (e.g. motorcycles). Although social acceptance of drink-driving has become very low, society is even less forgiving of professional drivers who cause crashes resulting in injury when driving under the influence of alcohol (Bjerre \& Kostela, 2008; Eksler \& Janitzek, 2010). Therefore, it is of crucial importance that companies do their utmost to avoid alcohol-related crashes involving their vehicles. Further research would benefit from examining the relationship between self-reported crashes and drink driving in Bali.

The goods vehicle drivers also had a low perception of risk when overtaking. This may represent aggressive behavior, or at least indicate some level of frustration. This behavior, often manifested in traffic rule violations, may be classified as aggressive and aberrant, or at least may stem from emotions linked with frustration (Davey et al., 2006). All the items related to aggressive driving behavior, driving errors, traffic rule violations and normlessness were positively and generally significant. This suggests that while these four factor structures are usually considered to be well defined, at some level they suggest related driving behaviors. For example, the differences between the items classified as traffic rule violations and aggressive driving behaviors were dependent upon the driving purposes and the environment (Davey et al., 2006).

Only a small proportion of the sample reported being in a crash within the last year, which contributed to difficulties in identifying the factors associated with the event. In addition, the time period for examining the incidence of crashes in this study may have been relatively short (that is, 1 year), accidents remain a relatively rare event. The most common forms of risky 
behavior of the goods vehicle drivers related to traffic crashes were speeding, taking risks when overtaking, and drink driving. This indicates that they had a low perception of traffic rules, so intentionally violated them. Interestingly, the drivers' responses in relation to drink driving at the weekend were positively connected with traffic crashes during working hours. This indicates that those drivers who drink alcohol portray aberrant behaviors (e.g. traffic rule violations and speeding), so are involved in traffic crashes.

Safety policies and practices within each organization are therefore required to encourage goods vehicle drivers to have higher perception of road safety risk. These may be implemented by promoting driver safety programs and road safety and educational campaigns. These programs may include improving driving and vehicle control skills, which in turn may increase driving ability. Road safety and educational campaigns may be focused on the risk of excessive speed on the road and the necessity to comply with speed limits. These policies and practices would certainly have a positive impact on traffic crash prevention.

\section{CONCLUSION}

The results of the study indicate that drink driving is positively related to traffic crashes during working hours. In addition, a greater number of items of normlessness influenced more than driving errors, aggresive behaviors and traffic rule violations on traffic crashes. These normlessness factors (i.e speeding behavior and taking risks when overtaking), however, may also reflect traffic rule violations, but do not necessarily reflect the situation that self-reported behaviors are only applicable to normlessness.

Further behavioral studies are required to analyze the contributing factors to traffic crashes involving drivers transporting goods and those transporting freight. In addition, a further comparative study is required to analyze the traffic crash involvement of drivers of passenger cars and buses and drivers transporting goods and freight.

\section{ACKNOWLEDGMENT}

Funding for this work was provided by the University of Udayana, Bali, Indonesia.

\section{REFERENCES}

Arnold, P.K., Hartley, L.R., Corry, A., Hochstadt, D., Penna, F., Feyer, A.M., 1997. Hours of Work and Perceptions of Fatigue among Truck Drivers. Accident Analysis and Prevention, Volume 29(4), pp. 471-477

Bjerre, B., Kostela. J., 2008. Primary Prevention of Drink Driving by the Large-scale Use of Alcolocks in Commercial Vehicles. Accident Analysis and Prevention, Volume 40(4), pp. 1294-1299

Darby, P., Murray, W., Raeside, R., 2009. Applying Online Fleet Driver Assessment to Help Identify, Target and Reduce Occupational Road Safety Risks. Safety Science, Volume 47(3), pp. 436-442

Davey, J., Freeman, J., Wishart, D., 2006. A Study Predicting Crashes among A Sample of Fleet Drivers. In: Proceedings Road Safety Research, Policing and Education Conference, Gold Coast, Queensland

Davey, J., Wishart, D., Freeman, J., Watson, B., 2007. An Application of the Driver Behavior Questionnaire in an Australian Organisational Fleet Setting. Transportation Research Part $F$, Volume 10(1), pp. 11-21

de Winter, J.C.F., Dodou, D., 2010. The Driver Behavior Questionnaire as a Predictor of Accidents: A Meta-analysis. Journal of Safety Research, Volume 41(6), pp. 463-470 
Eksler, V., Janitzek, T., 2010. Drink Driving in Commercial Transport. European Transport Safety Council

Freeman, J.E., Wishart, D.E., Davey, J.D., Rowland. B.D., 2008. Driving Safely for Work : A Study Investigating Aberrant Driving Behaviors within A Fleet Setting. In: Proceedings of CMRSC-XVIII, Whistler, Canada

Freeman, J.E., Wishart, D.E., Davey, J.D., Rowland, B.D., Williams, R., 2009. Utilising the Driver Behavior Questionnaire in an Australian Organisational Fleet Setting: Can It Identify Risky Drivers? Journal of the Australasian College of Road Safety, Volume 20(2), pp. 38-45

Glendon, A.I., Stanton, N.A., 2000. Perspectives on Safety Culture. Safety Science, Volume 34, pp. 193-214

Hooper, D., Coughlan, J., Mullen, M., 2008. Structural Equation Modelling: Guidelines for Determining Model Fit. Electronic Journal of Business Research Methods, Volume 6(1), pp. $53-60$

Indonesian National Police., 2014. Accident Data Report. Jakarta

Lajunen, T., Summala, H., 2003. Can We Trust Self-reports of Driving? Effects of Impression Management on Driver Behavior Questionnaire Responses. Transportation Research Part $F$, Volume 6(2), pp. 97-107

Matthews, G., Desmond, P.A., Joyner, L., Carcary, B., Kirby, G., 1997. A Comprehensive Questionnaire Measure of Driver Stress and Affect. In: Rothengatter, T., \& Vaya E.C. (Eds.) Traffic and Transport Psychology: Theory and Application, pp. 317-324

Newnam, S., Watson, B., Murray W., 2002. A Comparison of the Factors Influencing the Safety of Workrelated Drivers in Work and Personal Vehicles. In: Proceedings of the Road Safety Research, Policing and Education Conference, Adelaide, Transport South Australia

Parker, D., Stradling, S.G., Manstead, A., 1996. Modifying Beliefs and Attitudes to Exceeding the Speed Limit: An Intervention Study Based on the Theory of Planned Behaviour. Journal of Applied Social Psychology, Volume 26(1), pp. 1-19

Poulter, D.R., Chapman, P., Bibby, P.A., Clarke, D.D., Crundall, D., 2008. An Application of the Theory of Planned Behavior to Truck Driving Behavior and Compliance with Regulations. Accident Analysis and Prevention, Volume 40(6), pp. 2058-2064

Prochaska, J.O., DiClemente, C.C., 1984. The Transtheoritical Approach: Towards a Systematic Eclectic Framework. Dow Jones Irwin, Homewood, IL, USA

Reason, J., Manstead, A., Stradling, S., Baxter, J., Campbell, K., 1990. Errors and Violations on the Roads: A Real Distinction? Ergonomics, Volume 33(10-11), pp. 1315-1332

Rhodes, N., Pivik, K., 2011. Age and Gender Differences in Risky Driving: The Roles of Positive Affect and Risk Perception. Accident Analysis and Prevention, Volume 43(3), pp. 923-931

Statistics of Bali Province., 2015. Bali in Figures. Bali

Sullman, M.J.M., Meadows, M.L., Pajo, K.B., 2002. Aberrant Driving Behaviors amongst New Zealand Truck Drivers. Transportation Research Part F, Volume 5(3), pp. 217-232

The World Health Organization, 2015. Global Status Report on Road Safety 2015. Switzerland

Wishart, D.E., Davey, J.D., 2004. A Research Based Case Study Approach to the Development of Fleet Safety Interventions in Large Vehicle Fleets. In: Proceedings Safety in Action Conference, Melbourne, Victoria

Zuraida, R., Iridiastadi, H., Sutalaksana, I.Z., 2017. Indonesian Drivers' Characteristics Associated with Road Accidents. International Journal of Technology. Volume 8(2), pp. 311-319 